\title{
Correction to: Was the English medieval goat genuinely rare? A new morphometric approach provides the answer
}

\author{
Lenny Salvagno ${ }^{1}$ (D) $\cdot$ Umberto Albarella ${ }^{1}$ \\ Published online: 15 August 2019 \\ (C) Springer-Verlag GmbH Germany, part of Springer Nature 2019
}

\section{Correction to: Archaeological and Anthropological Sciences https://doi.org/10.1007/s12520-019-00843-2}

The original version of this article, unfortunately, contained errors. Figures 20, 21, 22, 23, 24, 25, 26, 27, 28, 29, 30, 31, 32, 33, 34 and 35 (Discriminant Analysis scatterplots) are incorrect: during the page lay-out design phase in all these figures, the centroid group lines (i.e. vertical lines which are blue for goats and red for sheep) were moved from their correct positions. To allow a correct interpretation of Figs. 20, 21, $22,23,24,25,26,27,28,29,30,31,32,33,34$ and 35 , the centroid group lines must cross the corresponding group centroid symbols.

The original article has been corrected.

The online version of the original article can be found at https://oi.org/ 10.1007/s12520-019-00843-2

Lenny Salvagno

1.salvagno@sheffield.ac.uk

1 Department of Archaeology, University of Sheffield, Minalloy, House, Sheffield, UK 

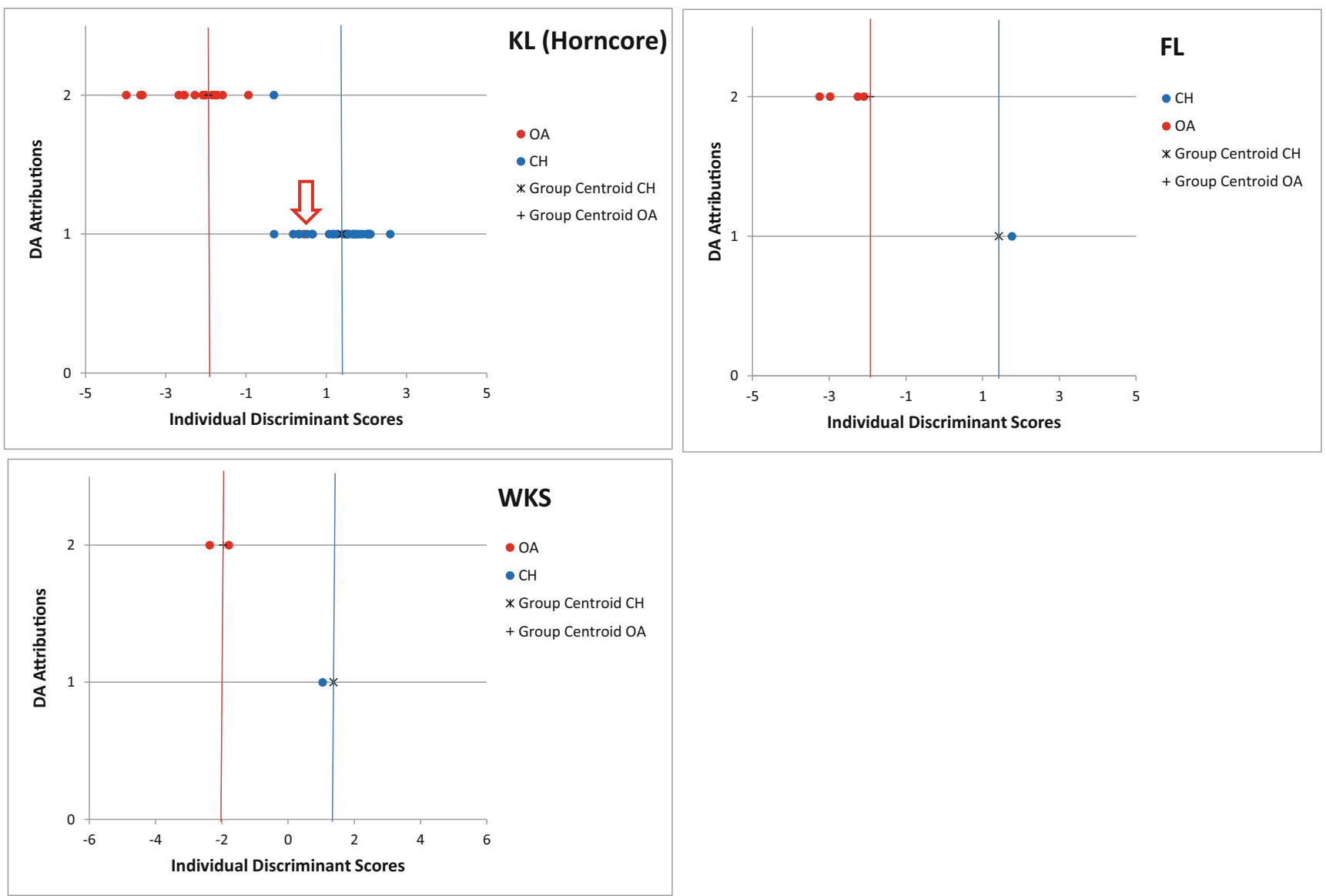

Fig. 20 Diagram of the LDA individual discriminant scores attributed to the archaeological material for the horncore. OA = Ovis aries (sheep), $\mathrm{CH}=$ Capra hircus (goat), KL = King's Lynn, FL = Flaxengate, WKS = Woolmonger/Kingswell Street 

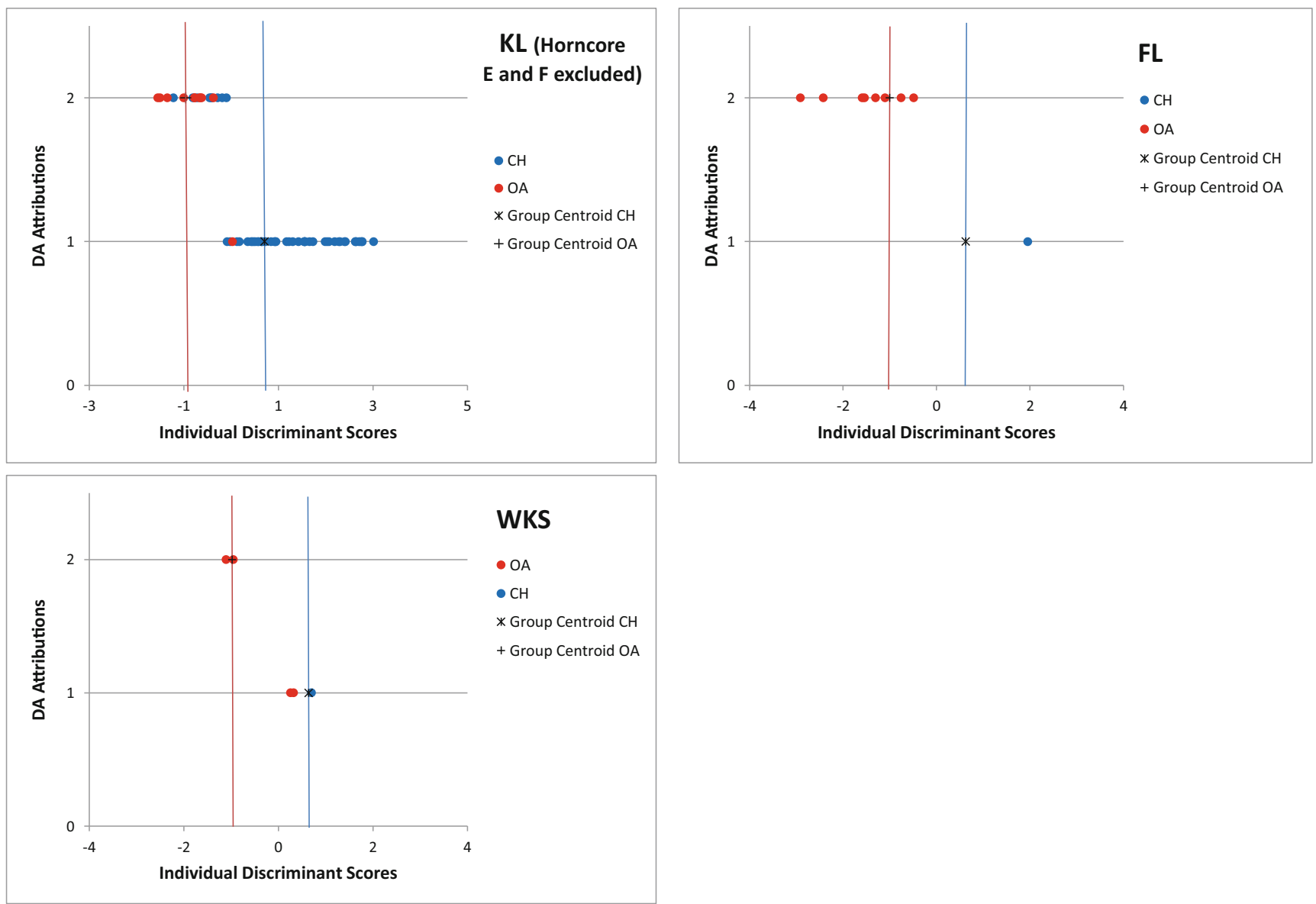

Fig. 21 Diagram of the individual discriminant scores attributed to the archaeological material by LDA for the horncore when variables E and $\mathrm{F}$ were excluded. Symbols are described in Fig. 20 

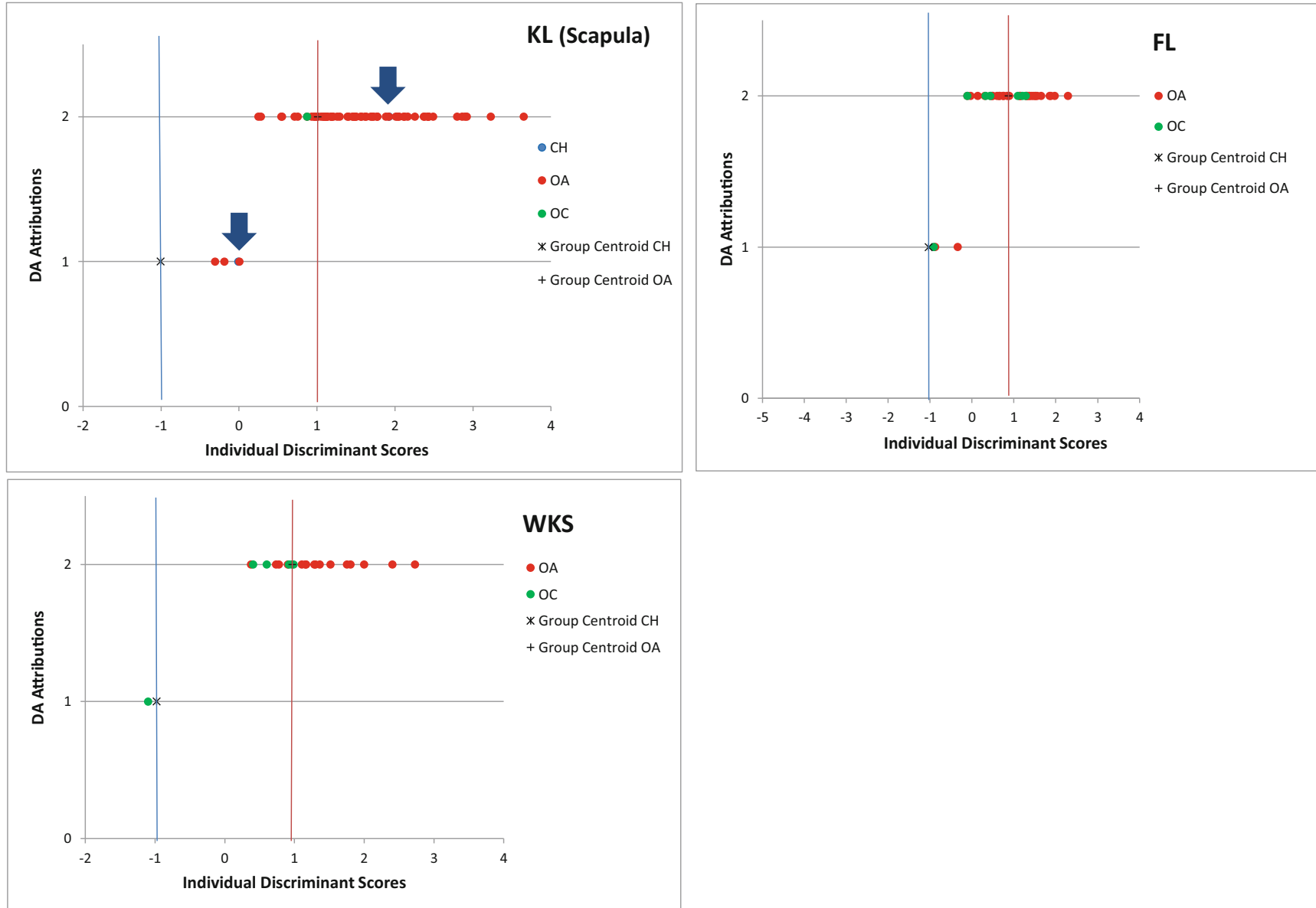

Fig. 22 Diagram of the individual discriminant scores attributed to the archaeological material by LDA for the scapula. Blue arrows indicate the position of the two archaeological goats. Symbols are described in Fig. 20 

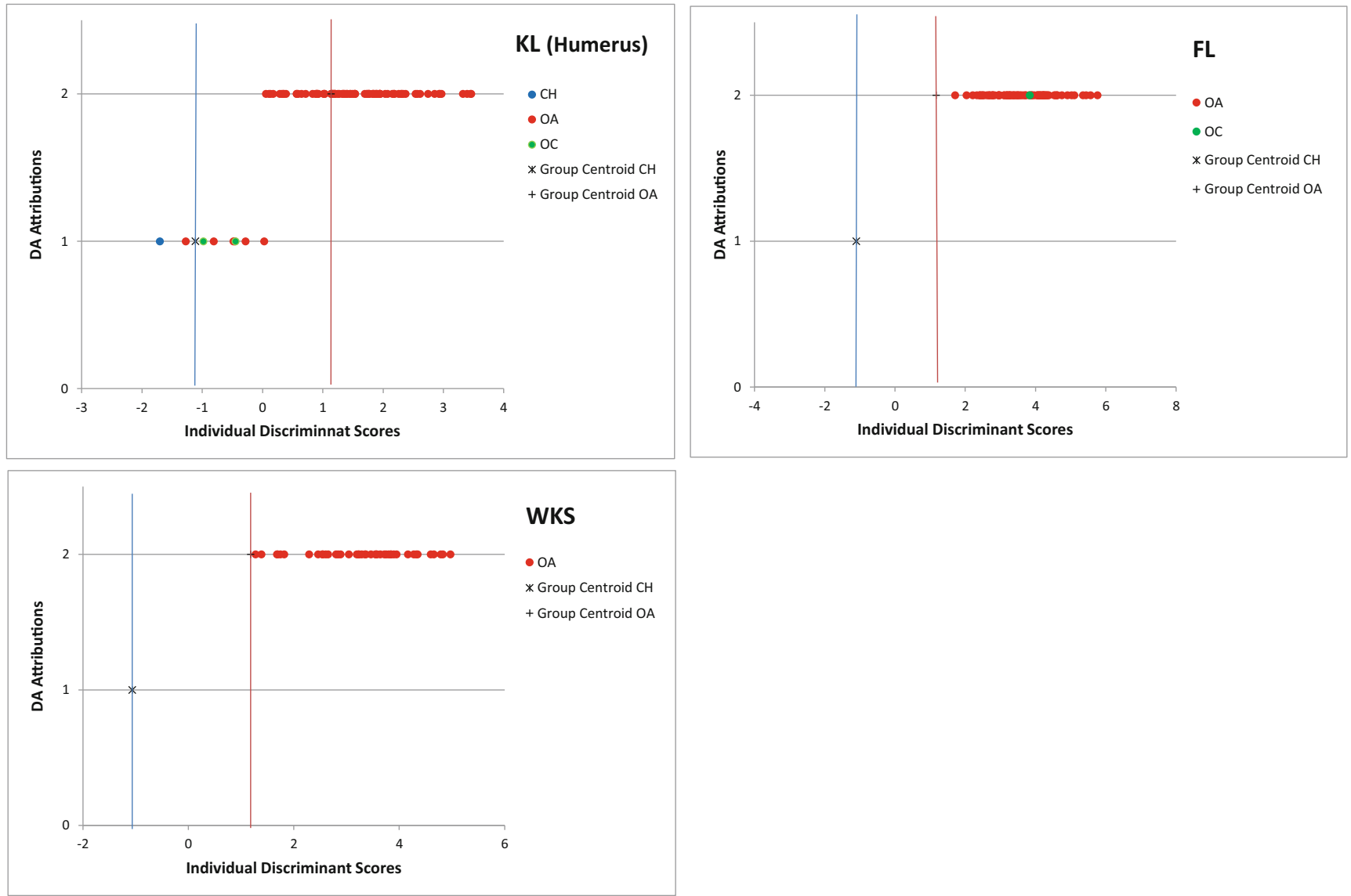

Fig. 23 Diagram of the individual discriminant scores attributed to the archaeologicalmaterial by LDA for the humerus. Symbols are described in Fig. 20 

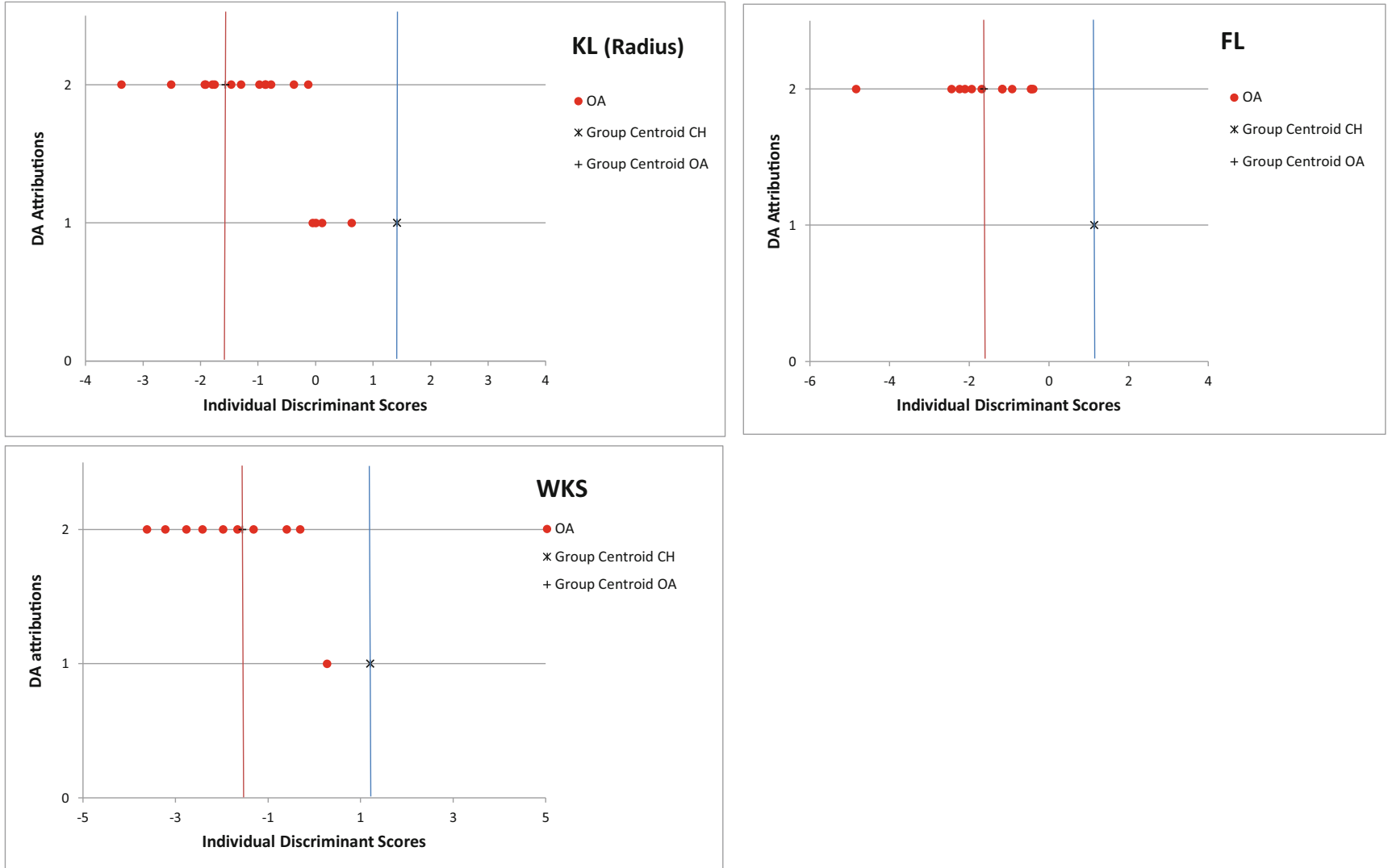

Fig. 24 Diagram of the individual discriminant scores attributed to the archaeological material by LDA for the radius. Symbols are described in Fig. 20 

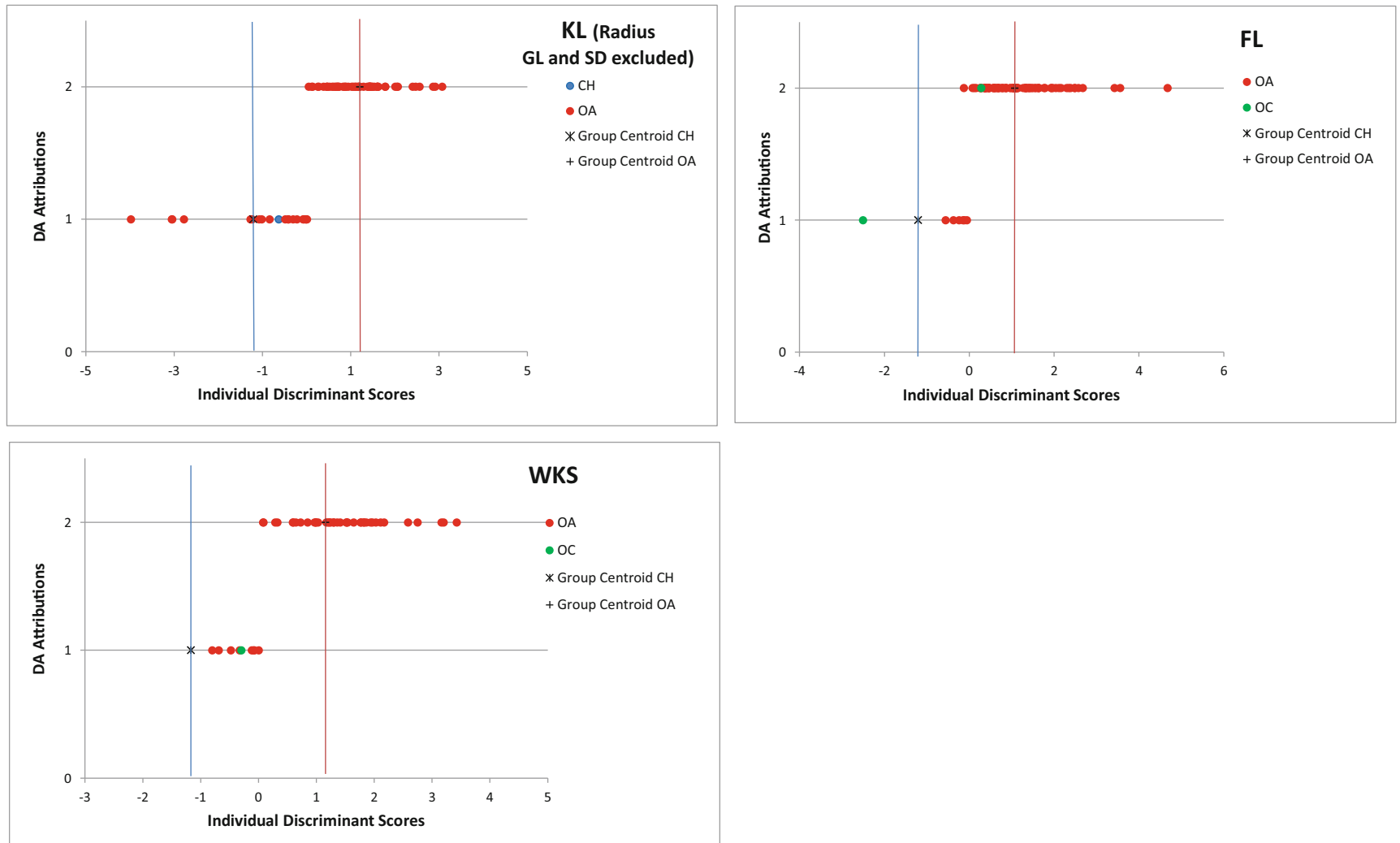

Fig. 25 Diagram of the individual discriminant scores attributed to the archaeological material by LDA for the radius when variables GL and SD were excluded. Symbols are described in Fig. 20 

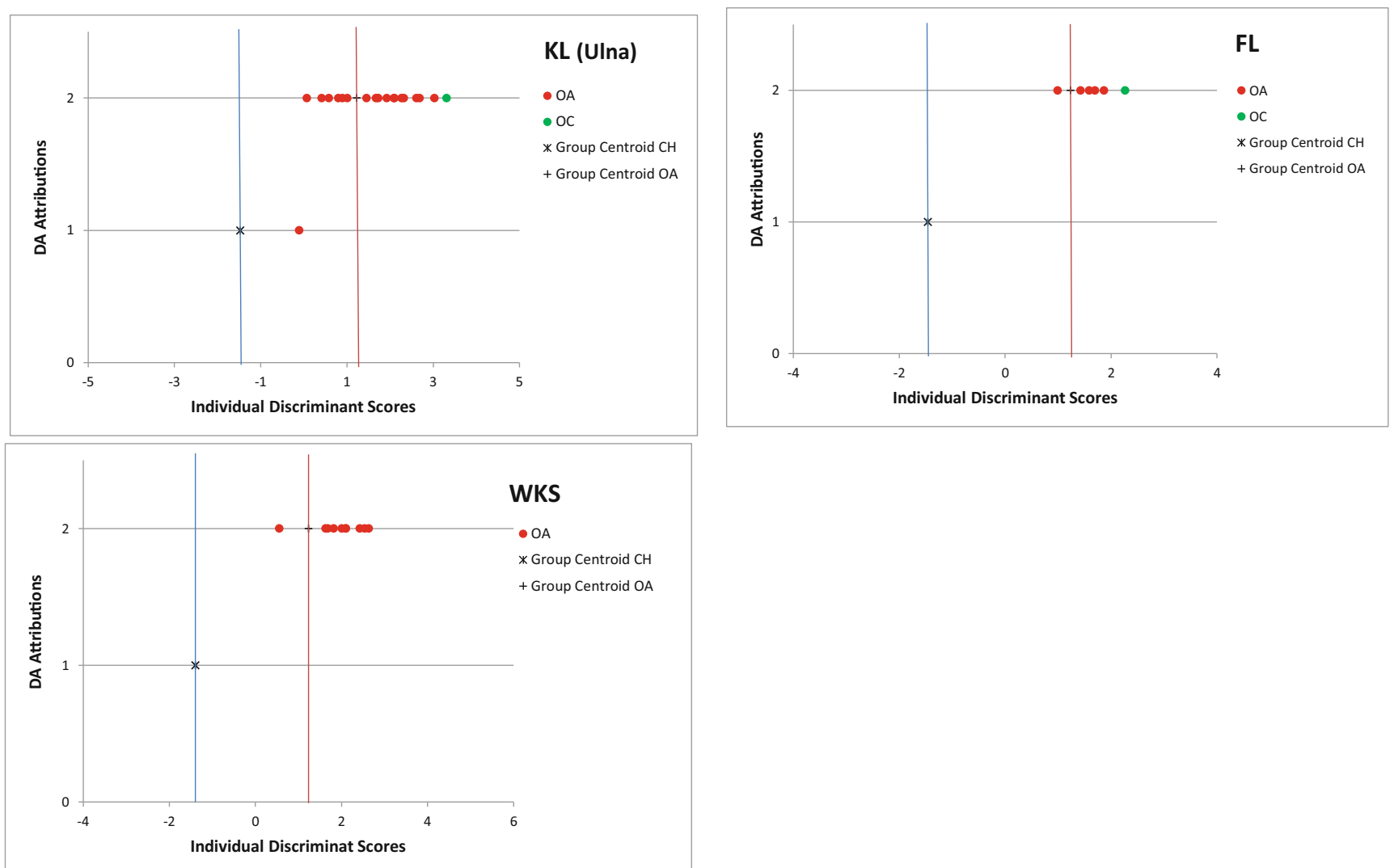

Fig. 26 Diagram of the individual discriminant scores attributed to the archaeological material by LDA for the ulna. Symbols are described in Fig. 20 

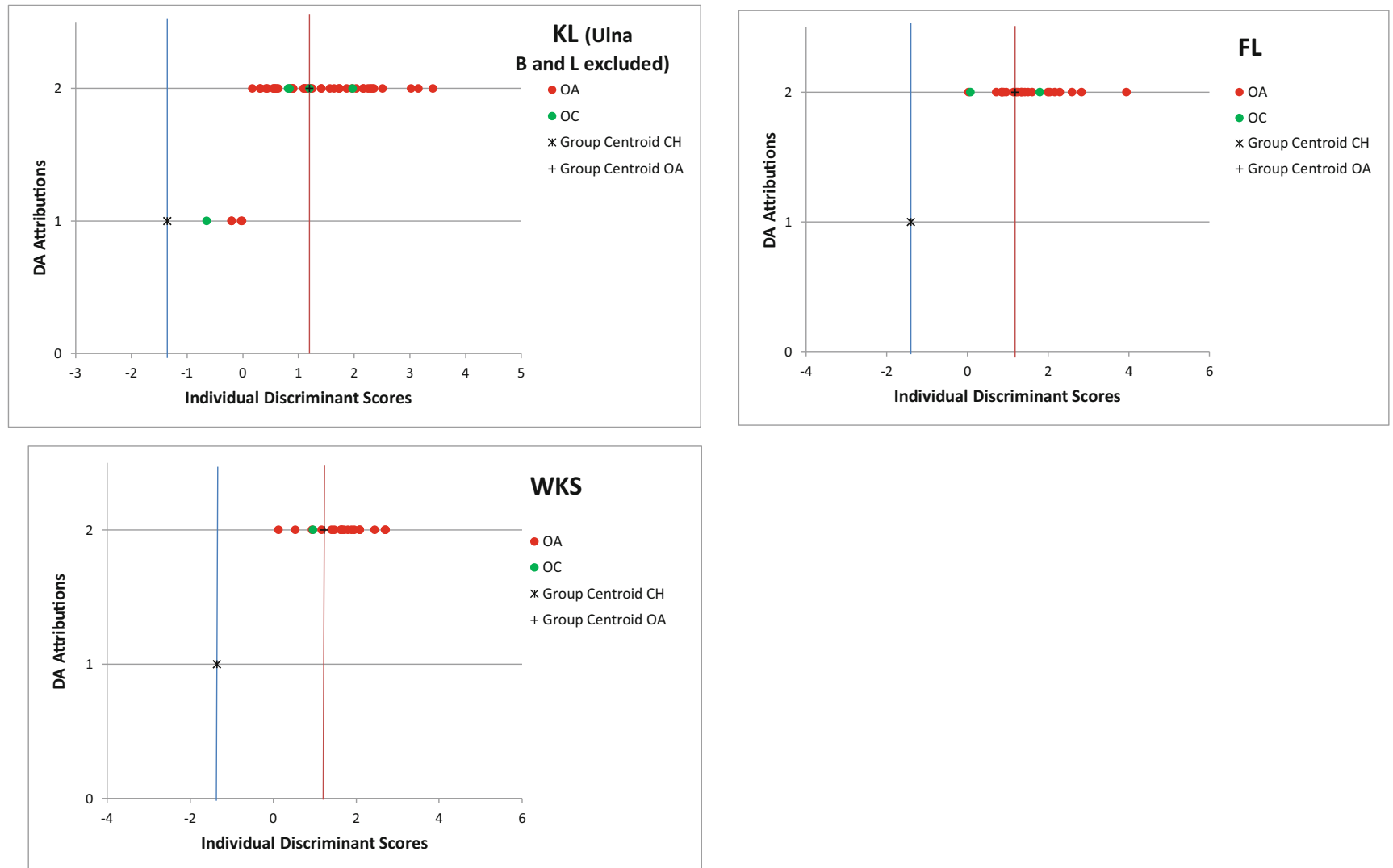

Fig. 27 Diagram of the individual discriminant scores attributed to the archaeological material by LDA for the ulna when variables B and L were excluded. Symbols are described in Fig. 20 

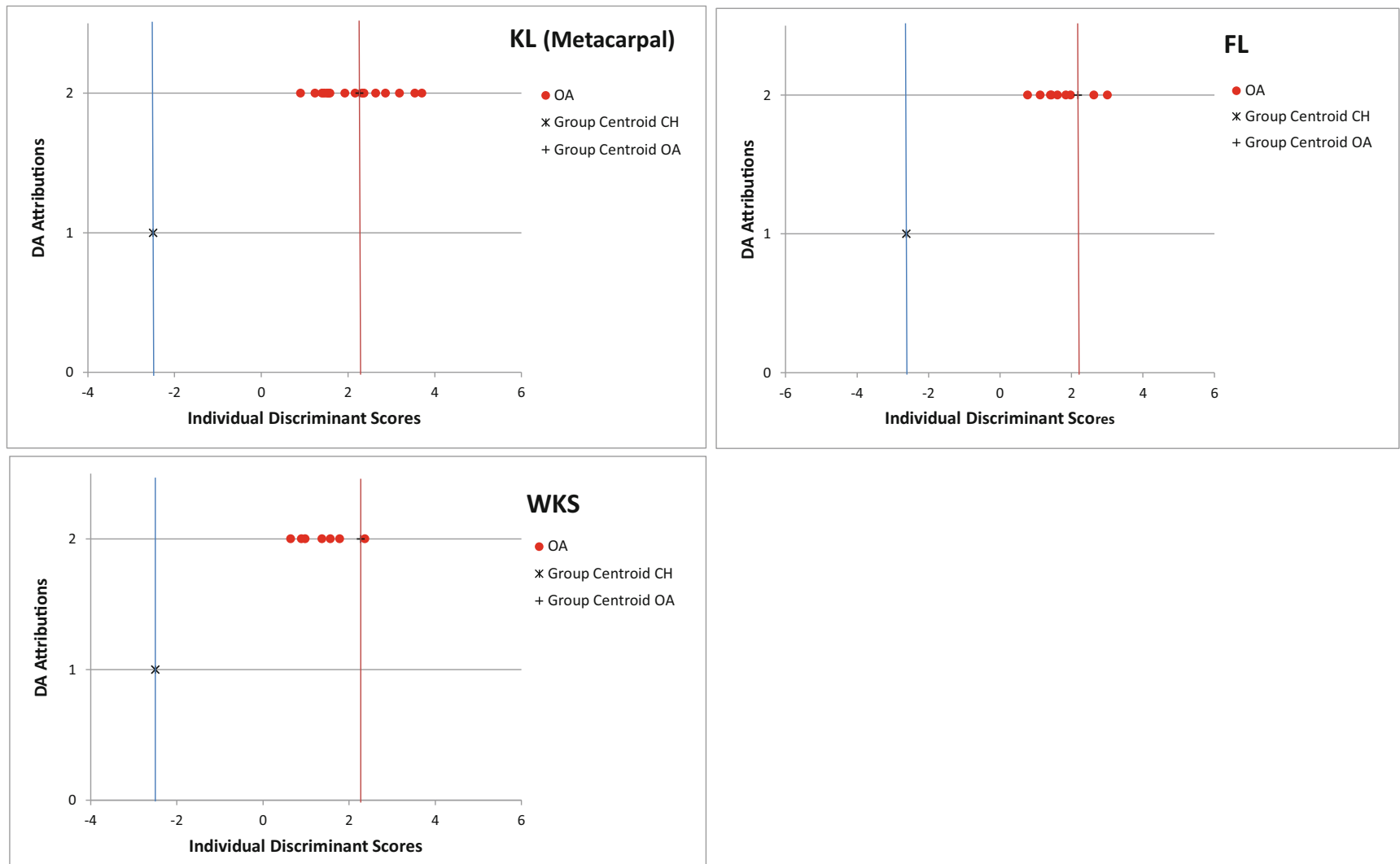

Fig. 28 Diagram of the individual discriminant scores attributed to the archaeological material by LDA for the metacarpal. Symbols are described in Fig. 20 

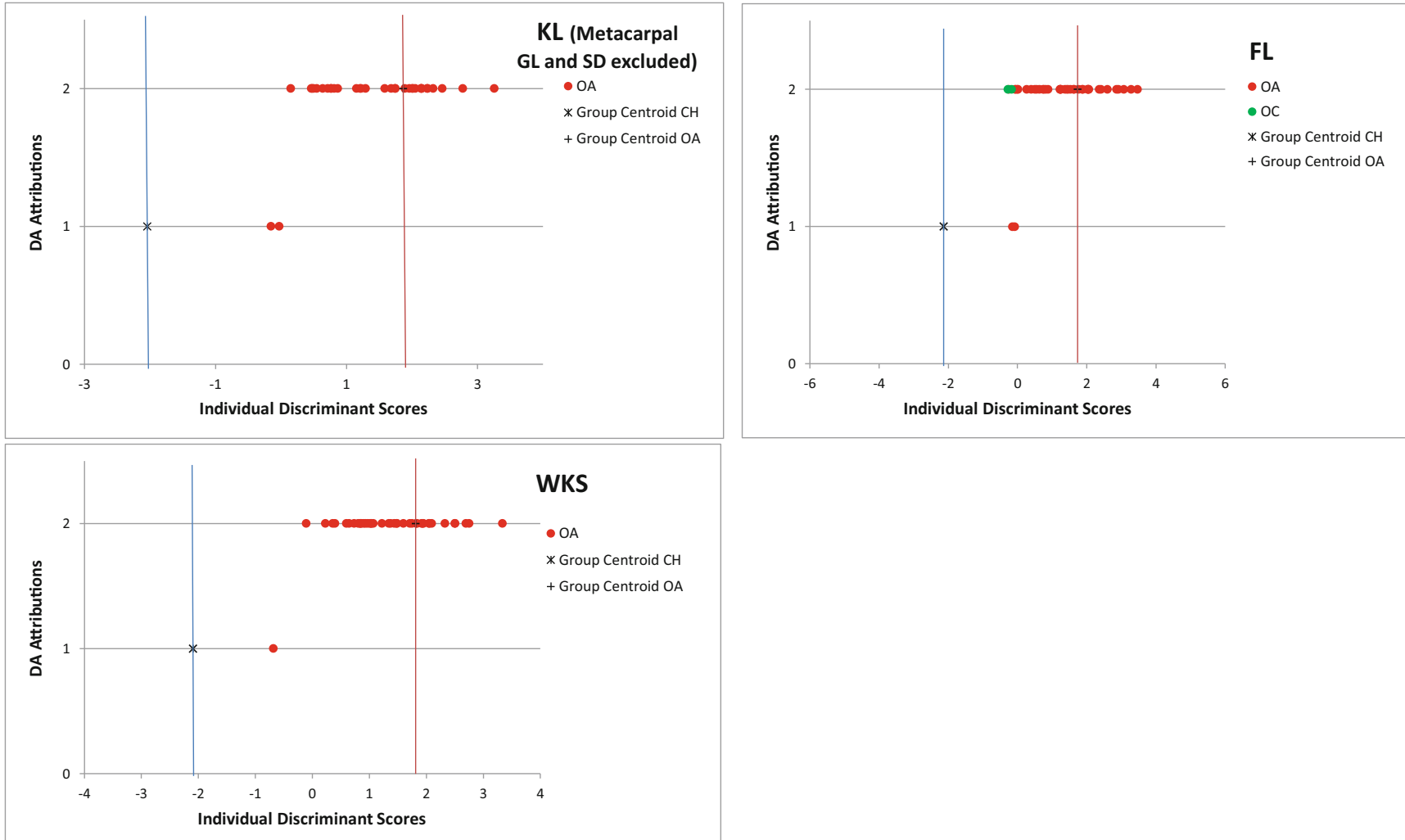

Fig. 29 Diagram of the individual discriminant scores attributed to the archaeological material by LDA for the metacarpal when variables GL and SD were excluded. Symbols are described in Fig. 20 

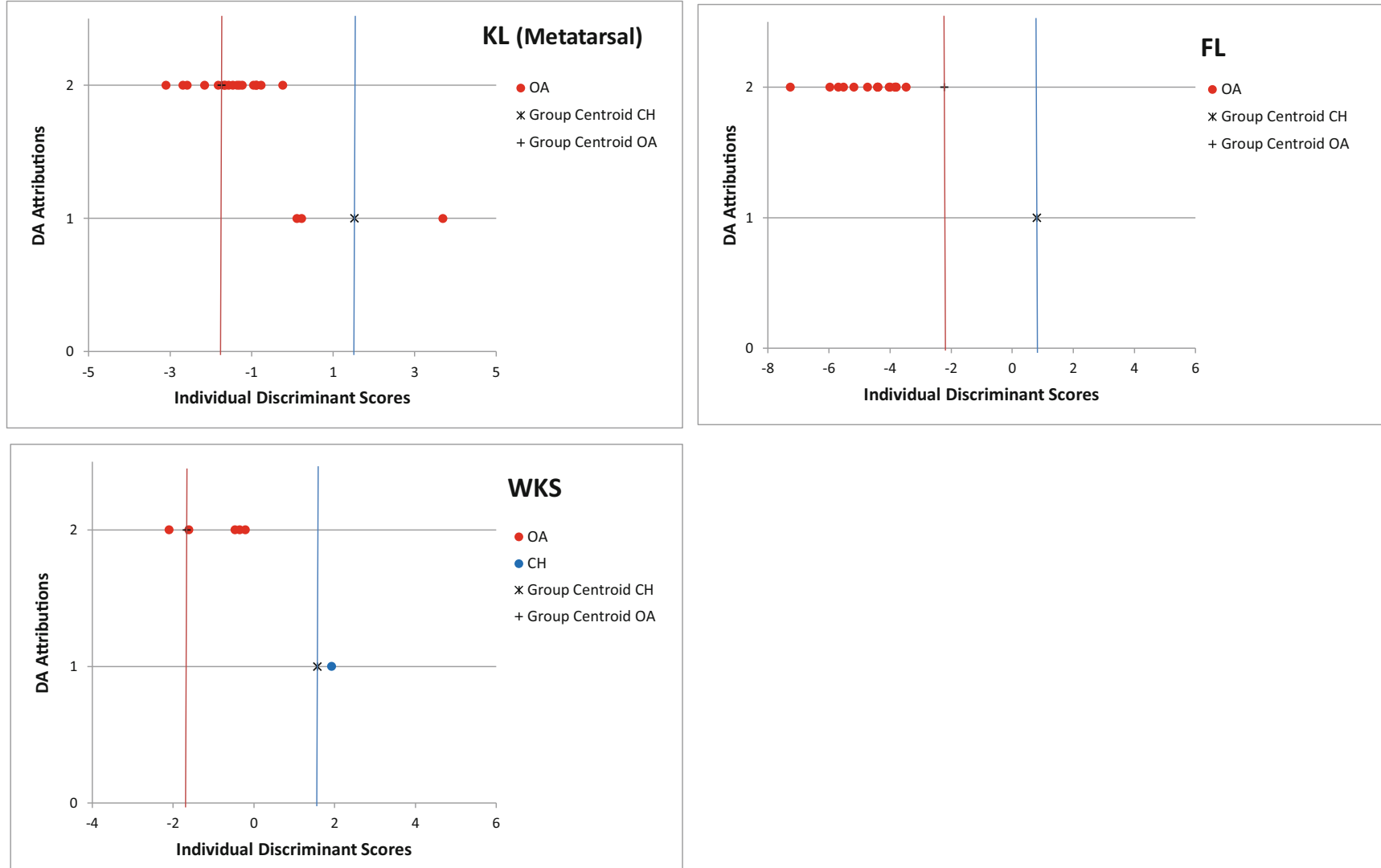

Fig. 30 Diagram of the individual discriminant scores attributed to archaeological material by LDA for the metatarsal. Symbols are described in Fig. 20 

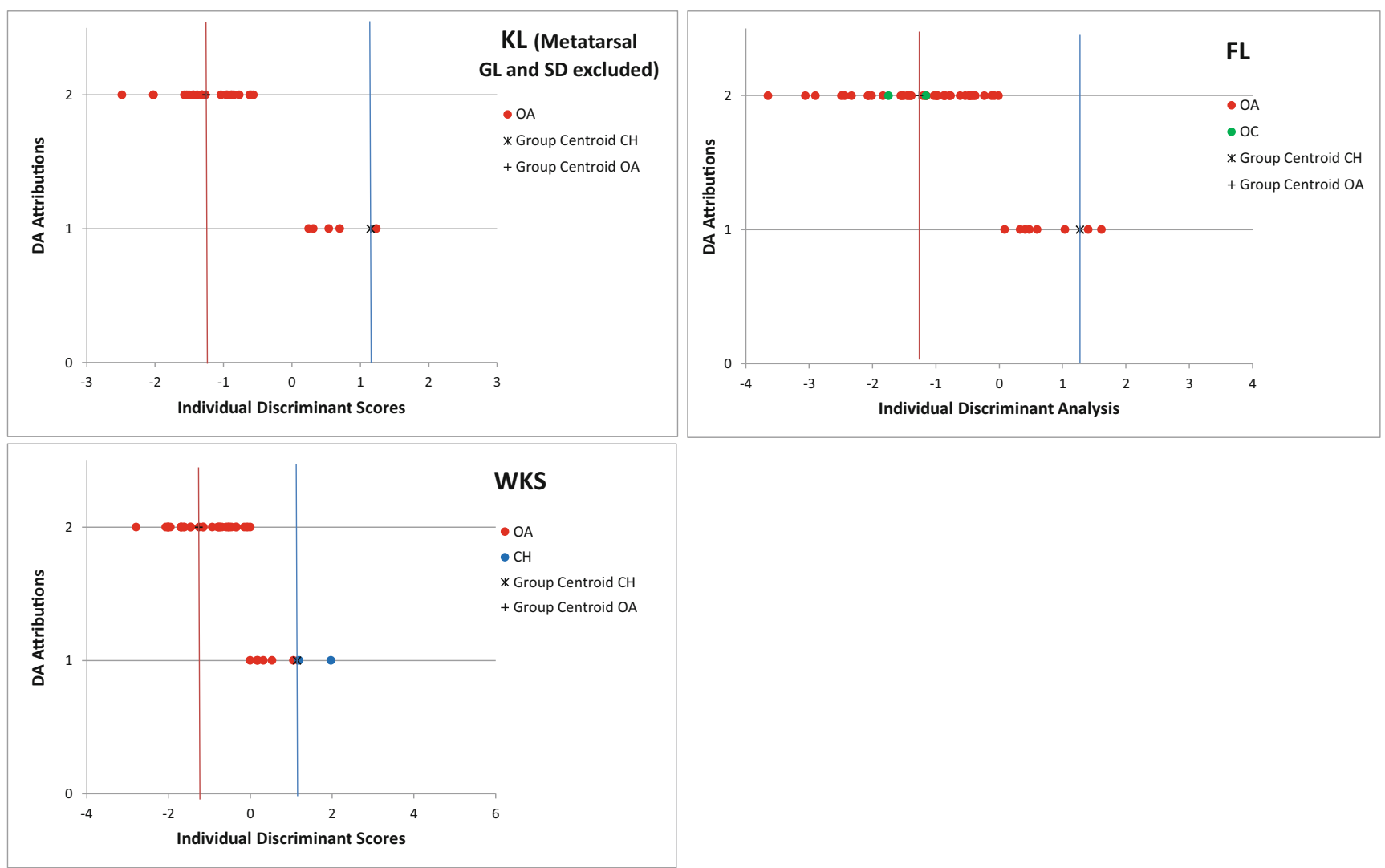

Fig. 31 Diagram of the individual discriminant scores attributed to the archaeological material by LDA for the metatarsal when variables GL and SD were excluded. Symbols are described in Fig. 20
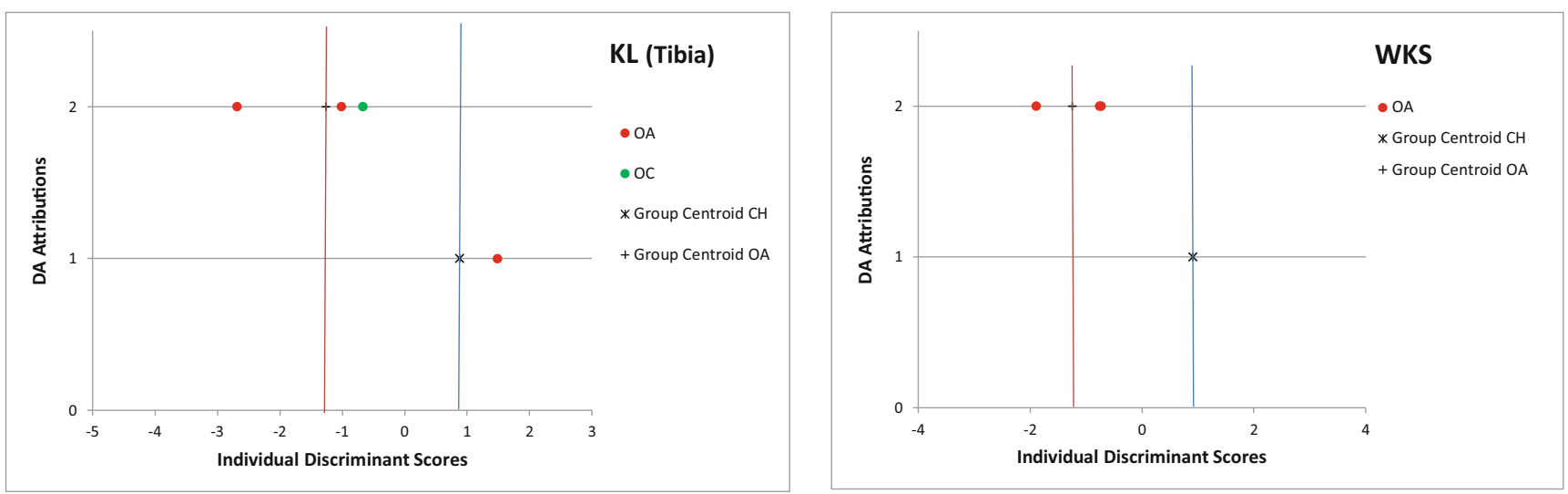

Fig. 32 Diagram of the individual discriminant scores attributed to the archaeological material by LDA for the tibia. No complete tibiae were recorded at FL. Symbols are described in Fig. 20 

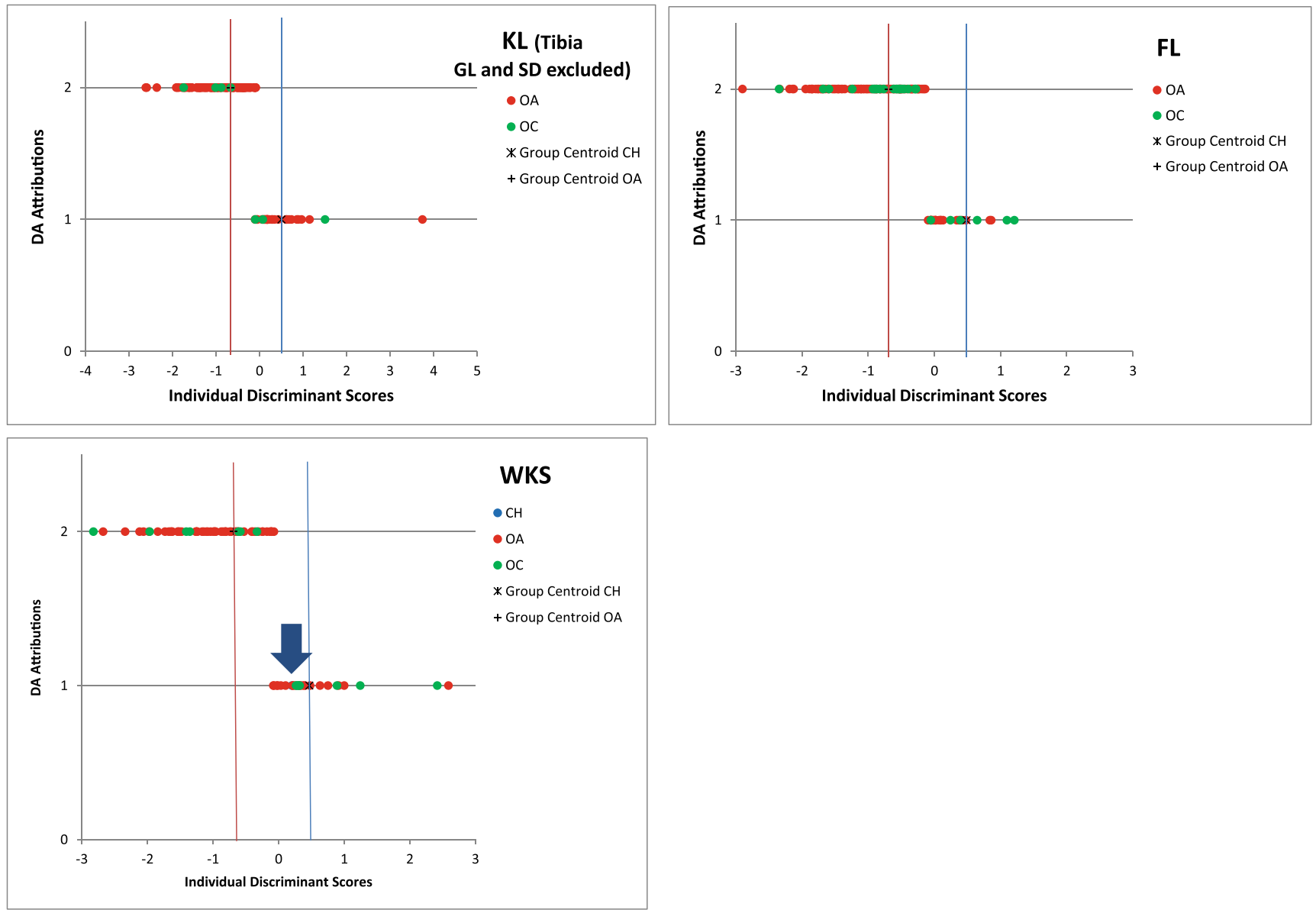

Fig. 33 Diagram of the individual discriminant scores attributed to the archaeological material by LDA for the tibia when variables GL and SD were excluded. Symbols are described in Fig. 20 

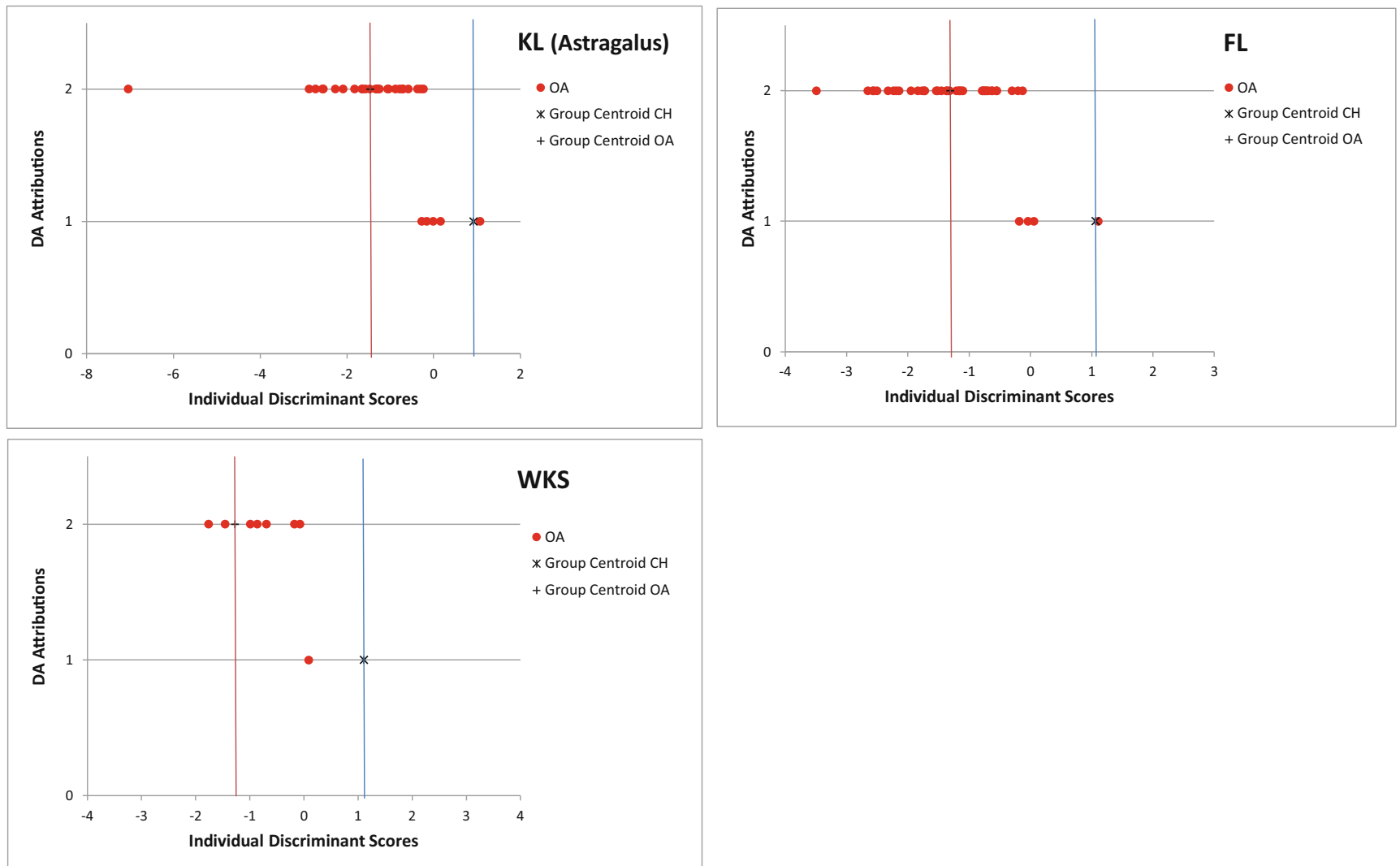

Fig. 34 Diagram of the individual discriminant scores attributed to the archaeological material by LDA for the astragalus. Symbols are described in Fig. 20 

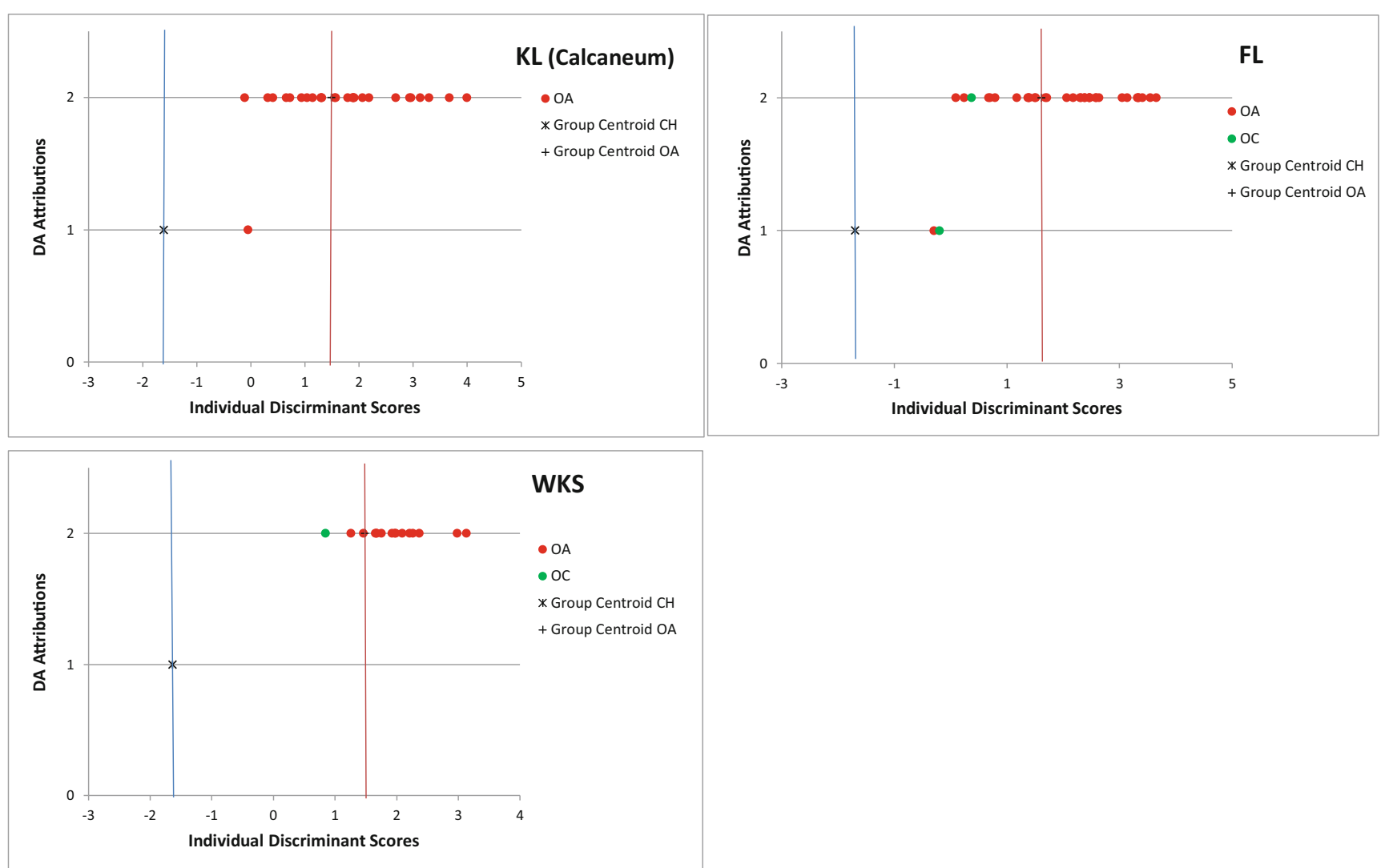

Fig. 35 Diagram of the individual discriminant scores attributed to the archaeological material by LDA for the calcaneum. Symbols are described in Fig. 20

Publisher's note Springer Nature remains neutral with regard to jurisdictional claims in published maps and institutional affiliations. 